\title{
Usefulness of endoscopic resection using the band ligation method for rectal neuroendocrine tumors
}

\author{
Ju Seung Kim ${ }^{1 *}$, Yoon Jae Kim*, Jun-Won Chung ${ }^{1}$, Jung Ho Kim ${ }^{1}$, Kyoung Oh Kim ${ }^{1}$, Kwang An Kwon ${ }^{1}$, \\ Dong Kyun Park ${ }^{1}$, Jung Suk An ${ }^{2}$ \\ Departments of ${ }^{1}$ Internal Medicine and ${ }^{2}$ Pathology, Gachon University College of Medicine, Gil Medical Center, Incheon, Korea
}

\begin{abstract}
Background/Aims: Rectal neuroendocrine tumors (NETs) are among the most common of gastrointestinal NETs. Due to recent advances in endoscopy, various methods of complete endoscopic resection have been introduced for small $(\leq 10 \mathrm{~mm})$ rectal NETs. However, there is a debate about the optimal treatment for rectal NETs. In our study, we aimed to evaluate the efficacy and feasibility of endoscopic resection using pneumoband and elastic band (ER-BL) for rectal NETs smaller than $10 \mathrm{~mm}$ in diameter. Methods: A total of 55 patients who were diagnosed with rectal NET from January 2004 to December 2011 at Gil Medical Center were analyzed retrospectively. Sixteen patients underwent ER-BL. For comparison, 39 patients underwent conventional endoscopic mucosal resection (EMR). Results: There was a markedly lower deep margin positive rate for ER-BL than for conventional EMR (6\% [1/16] vs. 46\% [18/39], $P=0.029)$. Four patients who underwent conventional EMR experienced perforation or bleeding. However, they recovered within a few days. On the other hand, patients whounderwent endoscopic resection using a pneumoband did not experience any complications. In multivariate analysis, ER-BL $(P=0.021)$ was independently associated with complete resection. Conclusions: ER-BL is an effective endoscopic treatment with regards to deep margin resection for rectal NET smaller than $10 \mathrm{~mm}$. (Intest Res 2016;14:164-171)
\end{abstract}

Key Words: Neuroendocrine tumors; Rectum; Pneumoband; Elastic band; Endoscopic mucosal resection

\section{INTRODUCTION}

Neuroendocrine tumors (NETs), also called carcinoid tumors, were described and defined as epithelial neoplasms with predominant neuroendocrine differentiation, and they can arise in most organs of the human body. ${ }^{1}$ However, $70 \%$ to $90 \%$ of NETs occur in the gastrointestinal (GI) tract. ${ }^{2,3}$ Rectal NET is a rare tumor with a relatively good prognosis, representing $1.8 \%$ of malignant anorectal neoplasms. ${ }^{4,5}$ Rectal NET is asymptomatic in over $50 \%$ of patients. Gener-

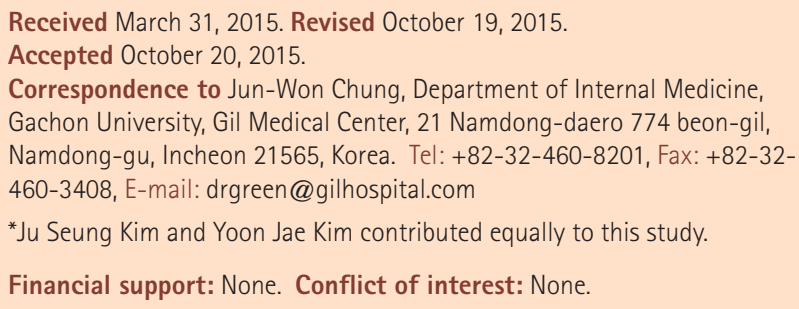

Financial support: None. Conflict of interest: None.

ally, rectal NETs are found incidentally during endoscopic examination. Recent improvements in endoscopic diagnosis and treatment procedures has facilitated the diagnosis of rectal NETs at an early stage. ${ }^{4,6}$ The typical endoscopic examination of rectal NETs reveals smooth, round, elevations covered with yellow-discolored mucosa. ${ }^{7}$

Several parameters have been suggested as being useful for predicting the malignant nature of rectal NETs, including size, endoscopic features, histological growth pattern, muscularis propria invasion, and lympho-vascular invasion. ${ }^{7,8}$ Among these parameters, tumor size has been proposed as the most important and reliable guide to malignancy of rectal NETs. ${ }^{9-11}$ According to a recent survey, metastasis is found in fewer than $3 \%$ of tumors that are $\leq 10 \mathrm{~mm}$ in diameter. ${ }^{12}$ The frequency increases to $80 \%$ for those that are $>20 \mathrm{~mm}^{5,13}$

Recent recommended therapeutic strategies for rectal NET suggest that endoscopic resection is appropriate for tumors that are $\leq 10 \mathrm{~mm}$ and confined to the submucosa,

\footnotetext{
๑ Copyright 2016. Korean Association for the Study of Intestinal Diseases. All rights reserved.

This is an Open Access article distributed under the terms of the Creative Commons Attribution Non-Commercial License (http://creativecommons.org/licenses/by-nc/4.0)

which permits unrestricted non-commercial use, distribution, and reproduction in any medium, provided the original work is properly cited.
} 
as they are judged to have low metastatic potential. ${ }^{14}$ Endoscopic mucosal resection (EMR) is the endoscopic treatment of choice for small rectal NETs. However, pathologically complete resection is not always easy using EMR because most rectal NETs are not limited to the mucosa, but rather, invade the submucosa. It is often necessary to perform additional treatments due to involvement of the resection margin ( $16 \%$ to $62 \%){ }^{13}$ Recently, various methods of endoscopic resection were introduced and studied, such as endoscopic submucosal dissection (ESD) and EMR using an elastic band (EMR-L). However, these treatments are still controversial because long-term outcomes for patients with $\leq 10$ $\mathrm{mm}$ rectal NETs without metastasis are poorly described in the literature. ${ }^{13,15}$

In this study, we compared the efficacy and feasibility of treatment between endoscopic resection using a pneumoband and an elastic band (ER-BL) and conventional EMR for rectal NETs smaller than $10 \mathrm{~mm}$.

\section{METHODS}

\section{Patients}

From January 2004 to December 2011, rectal NETs were diagnosed histopathologically after endoscopic examination followed by ER-BL or conventional EMR at Gil Medical Cen- ter. Rectal NETs $10 \mathrm{~mm}$ or less in size on endoscopy without distant metastases on abdominal CT were indications for endoscopic resection. We retrospectively reviewed the medical records of all of these patients. This study was conducted in accordance with the ethical principles of the Declaration of Helsinki and was approved by the ethics committee of Gachon University Gil Medical Center (Grant No. GCIRB 28702012).

\section{Resection Methods}

\section{1) ER-BL}

ER-BL and EMR-L were carried out with a single-channel scope (GIF-Q260 or H260, Olympus Medical Systems Co., Tokyo, Japan). Endoscopic resection using a pneumoband (ER-PB) was conducted as follows: after aspirating the lesion into the pneumoband cap with or without a submucosal injection of the solution ( $10 \%$ glycerin plus $5 \%$ fructose in $0.9 \%$ saline, a small amount of indigocarmine and epinephrine diluted to $1: 1: 100,000)$, the tumor was ligated with the pneumoband. A snare (SD-9U-1, Olympus Medical Systems Co.) was placed just below the pneumoband (MD-48709, Akita Sumitomo Bakelite Co., Ltd., Tokyo, Japan) and it was resected immediately using a high-frequency cutting current (Fig. 1).

EMR-L was conducted as follows: the lesion was elevated
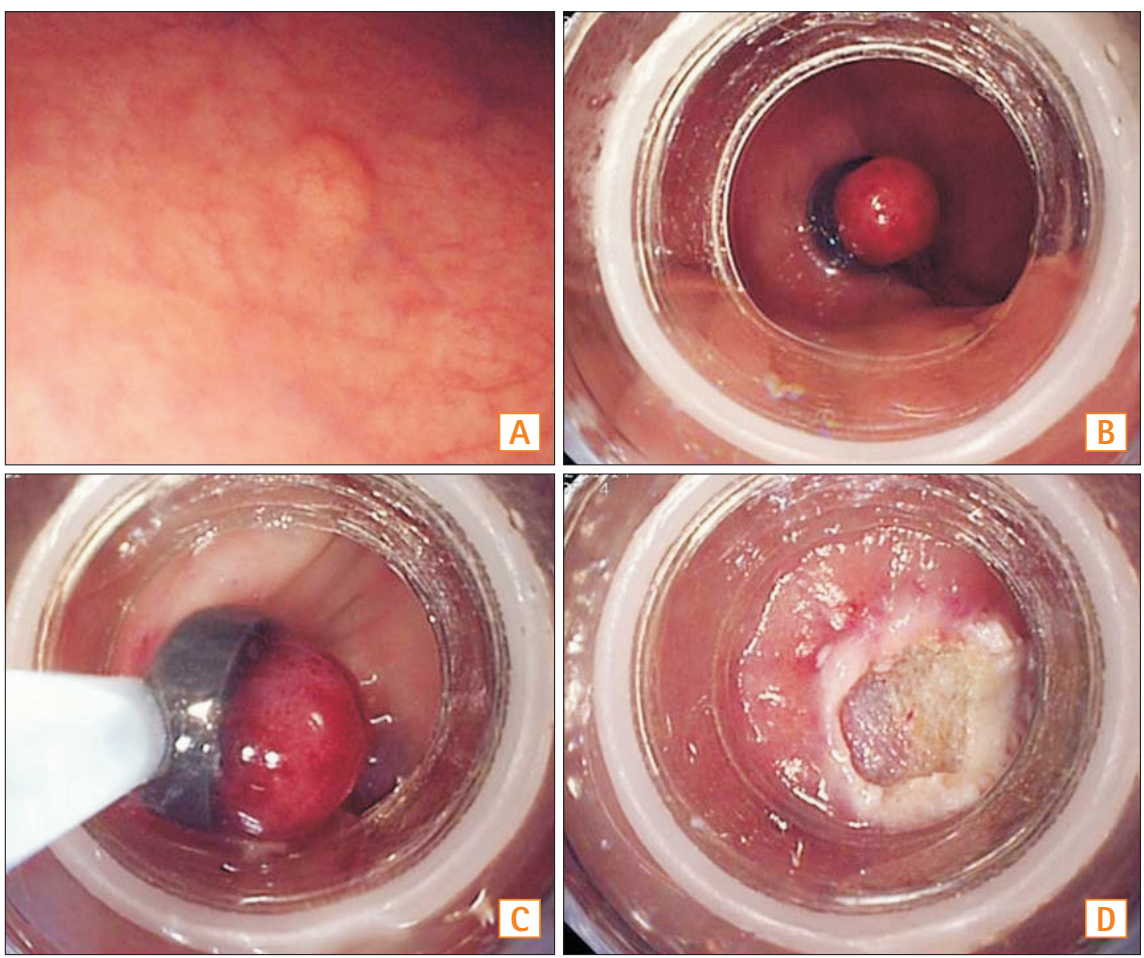

Fig. 1. Endoscopic resection using pneumoband (ER-PB). (A) Endoscopic view of an approximately 5 $\mathrm{mm}$ in diameter rectal NET. (B) The tumor is ligated with the pneumoband with or without submucosal injection. (C) The section immediately below the band is resected using a snare. (D) A post ER-PB ulcer. 
by submucosal injection of the same solution described above for ER-PB. After aspirating the lesion, the tumor was ligated with an elastic band (Stiegmann-goff Clearvue Endoscopic Ligator, ConMed, NY, USA). The section below the band was resected by using a high-frequency cutting current with the snare placed below the band (Fig. 2).

\section{2) Conventional EMR}

We used a single-channel scope (GIF-Q260 or H260, Olympus Medical Systems Co.). Conventional EMR was
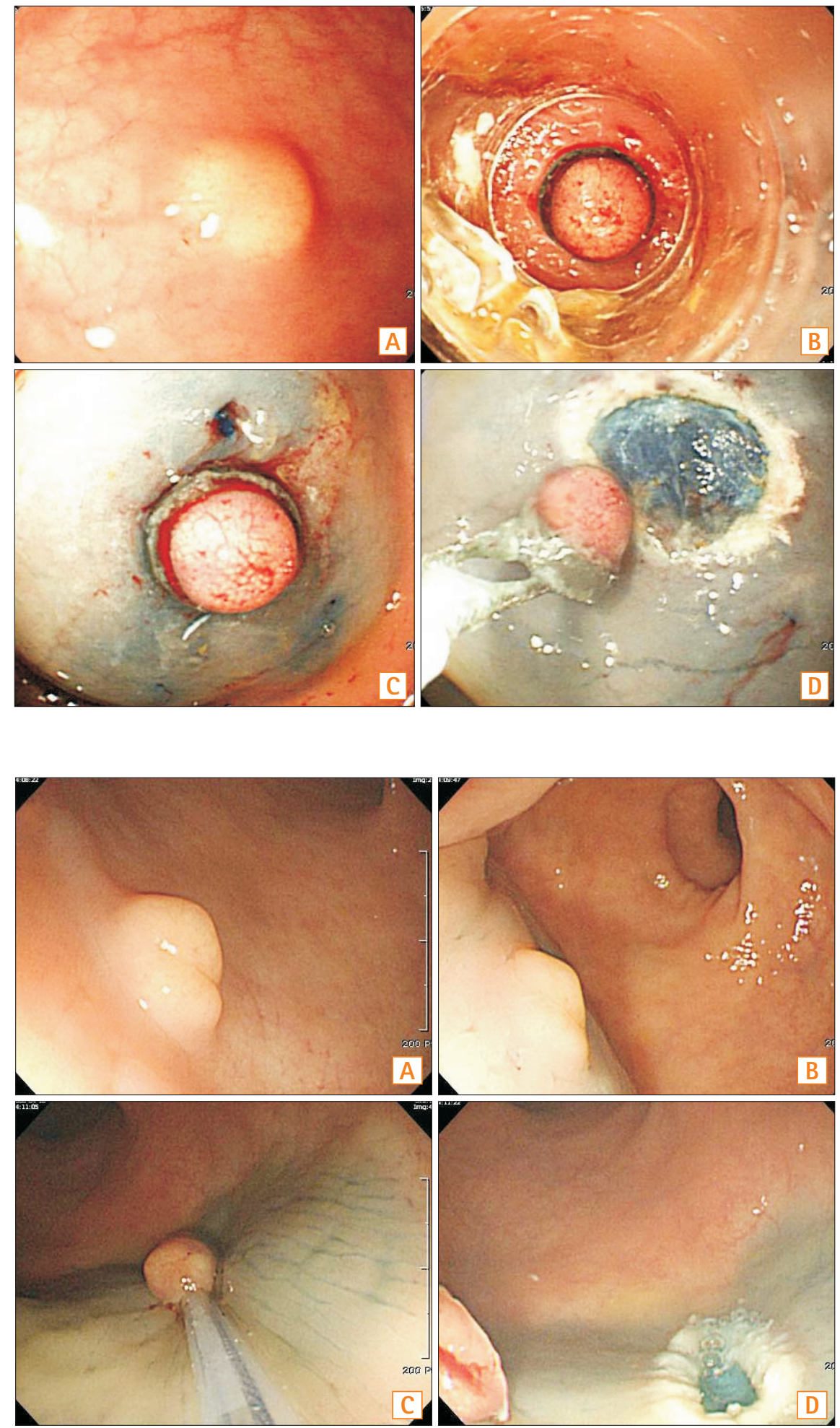

Fig. 2. Endoscopic resection using an elastic band. (A) Endoscopic view of an approximately $5 \mathrm{~mm}$ in diameter rectal NET. $(B, C)$ The tumor is aspirated and ligated with an endoscopic variceal ligation cap and band. (D) The section immediately below the band is resected using a snare.

Fig. 3. Conventional endoscopic mucosal resection. (A) Endoscopic view of an approximately $6 \mathrm{~mm}$ in diameter rectal NET. (B) Submucosal injection is performed. (C) Snaring of the elevated mucosal lesion is performed. (D) A post polypectomy ulcer. 
conducted as follows: the tumor was elevated by submucosal injection of the same solution described above for ER$\mathrm{PB}$. Then, the lesion was snared and resected using a highfrequency cutting current (Fig. 3).

\section{Outcomes}

The primary end-point of this study was the complete resection rate, including the lateral and deep resection margin in resected rectal NETs. Complete resection was defined as the existence of normal tissue in the mucosa or submucosa surrounding both the lateral and deep margins of the tumor without any tumor cells in the resection margin on microscopy. All histopathological appearances were thoroughly examined by a GI pathologist at our institution. The secondary end-point was complications such as bleeding or perforation.

\section{Follow-up}

To evaluate recurrences, periodic follow-up endoscopy and abdominal CT were performed for all of the patients. The first follow-up examination was performed 6 months after endoscopic resection with endoscopy and abdominal CT. After that, endoscopy and abdominal CT were performed annually.

\section{Statistical Analysis}

Student's $t$-test was applied to estimate and compare age, tumor size, and distance from the anal verge (AV) between groups. The chi-squared test was performed for analysis of sex, ratio of positive resection margin, and complications. Factors evaluated for complete resection by univariate analysis were sex, age, method, color, size, ulceration, and complications. Multivariate analysis including all predictors from the univariate analysis was assessed by multiple logistic regression analysis, and the OR with 95\% CI was determined. A $P$-value $<0.05$ was considered significant. All analyses were conducted using SPSS software (SPSS II v.12; SPSS Inc., Chicago, IL, USA).

\section{RESULTS}

\section{Demographic and Clinical Characteristics}

Over the 8 years from January 2004 to December 2011, 59 patients at Gil Medical Center were diagnosed with rectal NET. Among 59 patients, four patients received other treatments. Two patients underwent radical surgery involving a low anterior resection. As one patient's tumor had spread to the liver, she was referred for chemotherapy. Moreover, another patient refused treatment. Consequently, 55 patients received endoscopic resection for rectal NET. Sixteen patients underwent ER-BL. For comparison, 39 patients underwent conventional EMR. The demographic characteristics of the 55 enrolled patients are summarized in Table 1. All patients were asymptomatic and none had symptoms or signs of carcinoid syndrome. There was no significant difference in the age, sex, tumor size, distance from the AV, or tumor color between these two groups.

\section{Endoscopic Ultrasonographic Findings}

Among 59 patients, nine patients underwent EUS. Two patients who were confirmed to have submucosal invasion on the EUS underwent surgery. Seven patients were confirmed to have a hypoechoic lesion smaller than $1 \mathrm{~cm}$ in the submucosa without lymph node involvement.

\section{Endoscopic Findings and Clinical Outcomes}

All the tumors were removed in an en bloc manner. Significantly, the rate of positive deep resection margins was one patient (6\%) in the ER-BL group and $18(46 \%)$ in the conventional EMR group $(P=0.029)$ (Table 2). A patient with a positive deep resection margin in the ER-BL underwent low anterior resection. Eighteen patients with a positive deep resection margin on conventional EMR underwent the following additional treatments: low anterior resection (one

Table 1. Demographic Characteristics in Patients With Rectal Neuroendocrine Tumor

\begin{tabular}{lccc}
\hline \multicolumn{1}{c}{ Characteristic } & ER-BL & $\begin{array}{c}\text { Conventional } \\
\text { EMR }\end{array}$ & $P$-value \\
\hline Age & $51.75 \pm 10.57$ & $51.06 \pm 11.68$ & 0.106 \\
Male gender & $10 / 16(63)$ & $25 / 39(64)$ & 0.570 \\
Tumor size (cm) & & & \\
Width & $0.60 \pm 0.25$ & $0.58 \pm 0.45$ & 0.330 \\
Length & $0.64 \pm 0.27$ & $0.50 \pm 0.39$ & 0.322 \\
Distance (cm from AV) & $7.16 \pm 1.85$ & $7.00 \pm 3.51$ & 0.266 \\
Color & & & \\
Yellow & $7 / 16(44)$ & $21 / 39(54)$ & 0.503 \\
$\quad$ Normal & $9 / 16(56)$ & $18 / 39(46)$ & 0.389 \\
Ulceration & $1 / 16(6)$ & $1 / 39(2)$ & 0.189 \\
Metastasis & $0(0)$ & $0(0)$ & 0.594 \\
\hline
\end{tabular}

Values are presented as mean \pm SD or $n(\%)$.

$E R-B L$, endoscopic resection using pneumoband and elastic band; EMR, endoscopic mucosal resection; $A V$, anal verge. 
patient); just follow-up with colonoscopy and abdominal CT (14 patients); transferred to other hospital (two patients); and loss of follow-up (one patient) (Fig. 4). The 55 patients who underwent endoscopic resection all received follow-up endoscopy and abdominal CT. To date, there have been no recurrences and no patients have received additional interventions.

Table 2. Endoscopic Findings in Patients With Rectal Neuroendocrine Tumor Resected by ER-BL or Conventional EMR

\begin{tabular}{lccc}
\hline \multicolumn{1}{c}{ Variable } & ER-BL & $\begin{array}{c}\text { Conventional } \\
\text { EMR }\end{array}$ & $\boldsymbol{P}$-value \\
\hline En-bloc resection & $16(100)$ & $39(100)$ & \\
Deep resection margin (+) & $1 / 16(6)$ & $18 / 39(46)$ & 0.029 \\
Recurrence & $0(0)$ & $0(0)$ & \\
Complication & $0(0)$ & $4 / 39(10)$ & 0.481 \\
\hline
\end{tabular}

Values are presented as $n(\%)$.

$E R-B L$, endoscopic resection using pneumoband and elastic band; EMR, endoscopic mucosal resection.

\section{Adverse Events}

Four patients who underwent conventional EMR experienced complications. Three patients experienced delayed bleeding and were treated using argon plasma coagulation. One patient experienced perforation. We did hemoclipping immediately. Consequently, the patient recovered within a few days. On the other hand, patients who underwent ER-PB did not experience any complications (Table 2).

\section{Factors Affecting the Success of Complete Resection}

To investigate the independent factors affecting a successful complete resection, stepwise forward multiple logistic regression analysis was performed. Sex, age, method, color, size, ulceration or not, and complications were analyzed. Among these even factors, ER-PB remained significant in multivariate analysis (OR [95\% CI], 2.541 [1.219-4.751], $P=0.021$ ) (Table 3).

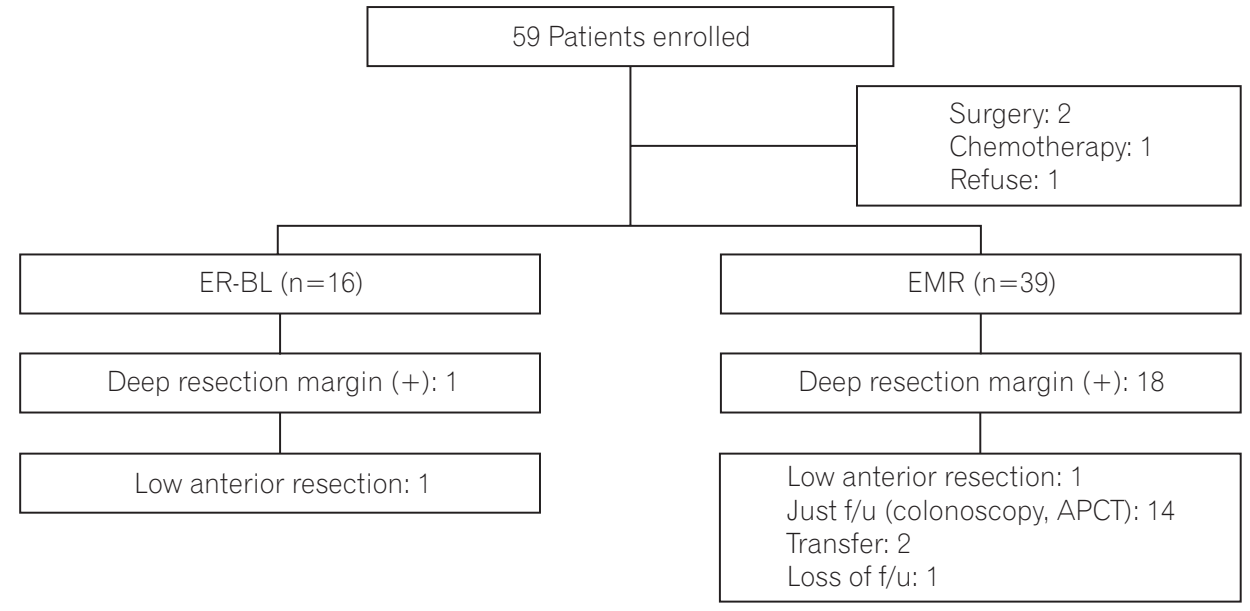

Fig. 4. Flow chart of rectal neuroendocrine tumor patients who underwent endoscopic resection. ER-BL, endoscopic resection using pneumoband and elastic band; EMR, endoscopic mucosal resection; f/u, follow up; APCT, abdominopelvic CT.

Table 3. Univariate and Multivariate Analyses of Factors Affecting the Sucess of Complete Resection

\begin{tabular}{|c|c|c|c|c|}
\hline Variable & \multicolumn{2}{|c|}{ Univariate analysis } & \multicolumn{2}{|c|}{ Multivariate analysis } \\
\hline Male gender & $0.619(0.684-2.111)$ & 0.273 & & \\
\hline Method (ER-BL) & $1.716(1.208-2.405)$ & 0.019 & 2.541 (1.219-4.751) & 0.021 \\
\hline Color (yellow) & 1.734 (0.127-4.003) & 0.280 & & \\
\hline Ulceration & 1.571 (0.107-3.094) & 0.320 & & \\
\hline Complication & $0.326(0.167-0.952)$ & 0.945 & & \\
\hline
\end{tabular}

ER-BL, endoscopic resection using pneumoband and elastic band. 


\section{DISCUSSION}

With the development of endoscopy, GI NETs have been discovered at an early stage. ${ }^{1}$ In general, rectal NETs less than $10 \mathrm{~mm}$ in diameter and a depth of invasion limited to the submucosa can be curatively treated by endoscopic resection. ${ }^{16,17}$ Furthermore, rectal NETs of less than $10 \mathrm{~mm}$ in size, without metastases or muscle invasion, are reported to have a good prognosis, with an almost 100\% 5-year survival rate. ${ }^{18,19}$ There is no definite guideline about endoscopic resection for patients diagnosed with small sized rectal NETs without metastasis. We show here that novel ER-PB could be an effective endoscopic resection method for rectal NETs smaller than $10 \mathrm{~mm}$.

NETs are characterized as slow-growing malignant neoplasms, being epithelial tumors composed of endocrine cells. ${ }^{20}$ GI NETs are frequently seen in the colorectal area, especially the rectum. One of the most common primary sites of GI NETs is the rectum within $10 \mathrm{~cm}$ of the anus. ${ }^{20}$ According to previous reports, risk factors for metastasis of rectal NET are: over $10 \mathrm{~mm}$ in diameter, muscular invasion, poorly differentiated neuroendocrine histology, and lympho-vascular invasion. ${ }^{5}$ However, rectal NETs estimated as $<10 \mathrm{~mm}$ in diameter with no atypical histology and confined to the submucosa without lympho-vascular invasion almost never metastasize. ${ }^{21,22}$

Due to recent advances in endoscopy technique, various methods of endoscopic resection were introduced and widely used. The representative methods are polypectomy and conventional EMR. Even though polypectomy and conventional EMR are quite simple, these techniques are sometimes associated with margin involvement and crush injury of the resected specimen, which leads to a need for an additional intervention. ${ }^{23,24}$ To overcome these shortcomings, various modified methods of endoscopic resections have been described. Especially, ESD and EMR-L result in good outcomes for rectal NETs less than $10 \mathrm{~mm} .^{13,25}$

ESD was originally developed to obtain one-piece resection for early gastric cancer. ${ }^{26}$ ESD is a superior method and has the advantage of permitting en bloc and histologically complete resection, compared with other endoscopic interventions. ESD can control the depth of submucosal dissection under endoscopic view. In this respect, it is clear that ESD is a useful therapeutic option for rectal NET. ${ }^{16,27}$ However, ESD has the disadvantage of a long procedural time and a considerably high risk of perforation as well as demanding a high level of technical skill. ${ }^{25,28}$
Theoretically, by adding a ligation process, EMR-L should be able to safely and completely resect the lesion and submucosal layer. Compared with conventional EMR and polypectomy, EMR-L can remove a deeper part of the submucosal layer. ${ }^{13,15}$ Some studies show that EMR-L is as effective as ESD for treatment of rectal NETs less than $10 \mathrm{~mm}$ in diameter showing invasion up to the submucosa without complications such as bleeding or perforation. ${ }^{23}$ However, there are still certain cases that exhibit a positive resection margin, and it has a risk of bleeding and perforation greater than that of polypectomy and conventional EMR. ${ }^{15,29}$

Pneumoband (PB), also called pneumo-active band, is commonly used in variceal bleeding. ${ }^{30} \mathrm{~PB}$ can be used in various endoscopic interventions. Recently, PB was attempted for treating non-variceal bleeding such as MalloyWeiss syndrome and after perforation as a salvage technique after endoclip failure. ${ }^{31}$ ER-PB has many advantages when compared to other endoscopic interventions. First, ER-PB is technically easier to use than other methods, with the lesions well viewed under direct pressure and suction from the ligation cap. ${ }^{32}$ Second, other endoscopic devices such as a snare or a catheter for electrohemostasis can be used through the same channel when needed. Third, ER-PB might secure a clearer view due to the wider ligation cap. On the basis of these theories, in this study, we compared patients with rectal NET treated with different methods. Consequently, this study shows that ER-BL has a better outcome than conventional EMR in regards to deeper resection margins and complications. Moreover, multivariate analysis revealed that ERBL was significantly associated with a successful complete resection.

However, there are some limitations to our study. First, our study is retrospective, non-randomized, and is a single-center study conducted on a small number of patients. Second ESD is known to be an efficient method for en bloc resection of large colorectal tumors. therefore ESD tends to increase gradually for rectal NET. Thus, there was no definite indication for choosing between conventional EMR and ER-BL.

In conclusion, ER-BL is a very effective method of endoscopic resection with regards to deep margin resection and a low rate of complications for rectal NETs less than $10 \mathrm{~mm}$ in diameter without metastasis. However, a large-scale, randomized, prospective, multicenter clinical study is necessary to confirm the feasibility and usefulness of ER-BL. 


\section{REFERENCES}

1. Modlin IM, Oberg K, Chung DC, et al. Gastroenteropancreatic neuroendocrine tumours. Lancet Oncol 2008;9:61-72.

2. Soga J. Early-stage carcinoids of the gastrointestinal tract: an analysis of 1914 reported cases. Cancer 2005;103:1587-1595.

3. Spitzer RL, Williams JB, Rieder R. Another perspective on "putting DSM-IV in perspective”. Am J Psychiatry 1999;156:499; author reply 500 .

4. Yamagishi D, Matsubara N, Noda M, et al. Clinicopathological characteristics of rectal carcinoid patients undergoing surgical resection. Oncol Lett 2012;4:910-914.

5. Kwaan MR, Goldberg JE, Bleday R. Rectal carcinoid tumors: review of results after endoscopic and surgical therapy. Arch Surg 2008;143:471-475.

6. Kobayashi K, Katsumata T, Yoshizawa S, et al. Indications of endoscopic polypectomy for rectal carcinoid tumors and clinical usefulness of endoscopic ultrasonography. Dis Colon Rectum 2005;48:285-291.

7. Shim KN, Yang SK, Myung SJ, et al. Atypical endoscopic features of rectal carcinoids. Endoscopy 2004;36:313-316.

8. Läuffer JM, Zhang T, Modlin IM. Review article: current status of gastrointestinal carcinoids. Aliment Pharmacol Ther 1999;13:271-287.

9. Söreide JA, van Heerden JA, Thompson GB, Schleck C, Ilstrup DM, Churchward M. Gastrointestinal carcinoid tumors: longterm prognosis for surgically treated patients. World J Surg 2000;24:1431-1436.

10. Koura AN, Giacco GG, Curley SA, Skibber JM, Feig BW, Ellis LM. Carcinoid tumors of the rectum: effect of size, histopathology, and surgical treatment on metastasis free survival. Cancer 1997;79:1294-1298.

11. Fitzgerald SD, Meagher AP, Moniz-Pereira P, Farrow GM, Witzig TE, Wolff BG. Carcinoid tumor of the rectum. DNA ploidy is not a prognostic factor. Dis Colon Rectum 1996;39:643-648.

12. Kim SH, Yang DH, Lee JS, et al. Natural course of an untreated metastatic perirectal lymph node after the endoscopic resection of a rectal neuroendocrine tumor. Intest Res 2015;13:175179.

13. Ono A, Fujii T, Saito Y, et al. Endoscopic submucosal resection of rectal carcinoid tumors with a ligation device. Gastrointest Endosc 2003;57:583-587.

14. Ramage JK, Goretzki PE, Manfredi R, et al. Consensus guidelines for the management of patients with digestive neuroendocrine tumours: well-differentiated colon and rectum tumour/ carcinoma. Neuroendocrinology 2008;87:31-39.
15. Mashimo Y, Matsuda T, Uraoka T, et al. Endoscopic submucosal resection with a ligation device is an effective and safe treatment for carcinoid tumors in the lower rectum. J Gastroenterol Hepatol 2008;23:218-221.

16. Fujishiro M. Perspective on the practical indications of endoscopic submucosal dissection of gastrointestinal neoplasms. World J Gastroenterol 2008;14:4289-4295.

17. Langer C, Liersch T, Süss M, et al. Surgical cure for early rectal carcinoma and large adenoma: transanal endoscopic microsurgery (using ultrasound or electrosurgery) compared to conventional local and radical resection. Int J Colorectal Dis 2003;18:222-229.

18. Scherübl H, Klöppel G. Rectal carcinoids on the rise - update. Z Gastroenterol 2009;47:365-371.

19. Konishi T, Watanabe T, Kishimoto J, et al. Prognosis and risk factors of metastasis in colorectal carcinoids: results of a nationwide registry over 15 years. Gut 2007;56:863-868.

20. Varas-Lorenzo MJ, Muñoz-Agel F, Espinós-Pérez JC, BardajíBofill M. Gastrointestinal carcinoid tumors. Rev Esp Enferm Dig 2010;102:533-537.

21. Schindl M, Niederle B, Häfner M, et al. Stage-dependent therapy of rectal carcinoid tumors. World J Surg 1998;22:628-633; discussion 634 .

22. Jetmore AB, Ray JE, Gathright JB Jr, McMullen KM, Hicks TC, Timmcke AE. Rectal carcinoids: the most frequent carcinoid tumor. Dis Colon Rectum 1992;35:717-725.

23. Choi CW, Kang DH, Kim HW, et al. Comparison of endoscopic resection therapies for rectal carcinoid tumor: endoscopic submucosal dissection versus endoscopic mucosal resection using band ligation. J Clin Gastroenterol 2013;47:432-436.

24. Iishi H, Tatsuta M, Yano H, Narahara H, Iseki K, Ishiguro S. More effective endoscopic resection with a two-channel colonoscope for carcinoid tumors of the rectum. Dis Colon Rectum 1996;39:1438-1439.

25. Akahoshi K, Motomura Y, Kubokawa M, et al. Endoscopic submucosal dissection of a rectal carcinoid tumor using grasping type scissors forceps. World J Gastroenterol 2009;15:2162-2165.

26. Ono H, Kondo H, Gotoda T, et al. Endoscopic mucosal resection for treatment of early gastric cancer. Gut 2001;48:225-229.

27. Onozato Y, Kakizaki S, Ishihara H, et al. Endoscopic submucosal dissection for rectal tumors. Endoscopy 2007;39:423-427.

28. Akahoshi K, Akahane H, Murata A, Akiba H, Oya M. Endoscopic submucosal dissection using a novel grasping type scissors forceps. Endoscopy 2007;39:1103-1105.

29. Moon JH, Kim JH, Park CH, et al. Endoscopic submucosal resection with double ligation technique for treatment of small rectal carcinoid tumors. Endoscopy 2006;38:511-514. 
30. Church NI, Palmer KR. Ulcers and nonvariceal bleeding. Endoscopy 2003;35:22-26.

31. Cho YS, Chae HS, Kim HK, et al. Endoscopic band ligation and endoscopic hemoclip placement for patients with MalloryWeiss syndrome and active bleeding. World J Gastroenterol 2008;14:2080-2084.
32. Park CH, Min SW, Sohn YH, et al. A prospective, randomized trial of endoscopic band ligation vs. epinephrine injection for actively bleeding Mallory-Weiss syndrome. Gastrointest Endosc 2004;60:22-27. 